\title{
A nested Atlantic-Mediterranean Sea general circulation model for operational forecasting
}

\author{
P. Oddo ${ }^{1}$, M. Adani ${ }^{1}$, N. Pinardi ${ }^{2}$, C. Fratianni ${ }^{1}$, M. Tonani ${ }^{1}$, and D. Pettenuzzo ${ }^{1}$ \\ ${ }^{1}$ Gruppo Nazionale di Oceanografia Operativa, Istituto Nazionale di Geofisica e Vulcanologia, Via Aldo Moro 44, \\ 40128 Bologna, Italy \\ ${ }^{2}$ Centro Interdipartimentale per la Ricerca in Scienze Ambientali, Università di Bologna Ravenna, Italy
}

Received: 25 May 2009 - Published in Ocean Sci. Discuss.: 15 June 2009

Revised: 7 September 2009 - Accepted: 6 October 2009 - Published: 26 October 2009

\begin{abstract}
A new numerical general circulation ocean model for the Mediterranean Sea has been implemented nested within an Atlantic general circulation model within the framework of the Marine Environment and Security for the European Area project (MERSEA, Desaubies, 2006). A 4year twin experiment was carried out from January 2004 to December 2007 with two different models to evaluate the impact on the Mediterranean Sea circulation of open lateral boundary conditions in the Atlantic Ocean. One model considers a closed lateral boundary in a large Atlantic box and the other is nested in the same box in a global ocean circulation model. Impact was observed comparing the two simulations with independent observations: ARGO for temperature and salinity profiles and tide gauges and along-track satellite observations for the sea surface height. The improvement in the nested Atlantic-Mediterranean model with respect to the closed one is particularly evident in the salinity characteristics of the Modified Atlantic Water and in the Mediterranean sea level seasonal variability.
\end{abstract}

\section{Introduction}

Simulating and forecasting Mediterranean Sea dynamics is challenging due to the very complex dynamics characterizing this semi-enclosed deep basin. In the past ten years, operational oceanography has become a reality in the Mediterranean Sea: the regional implementation plan (Pinardi and Flemming, 1998) has been accomplished and integrated observation and modelling has been carried out producing real time daily forecasts with multivariate data assimilation and

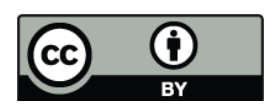

Correspondence to: P. Oddo (oddo@bo.ingv.it) nesting of sub-regional and shelf models (Pinardi et al., 2003). Operational modelling for forecasting allows continuous and quantitative assessment of the quality of the model simulations and this is expected to serve as the test bed for the development of new model solutions and parameterizations. This paper illustrates a major step in modelling the Mediterranean Sea, never before carried out, which considers one-way nesting in the Atlantic ocean with a global ocean forecasting system developed during the MERSEA project (Desaubies, 2006). Previous models of the Mediterranean Sea circulation have parameterized the connection with the Atlantic ocean in different ways (i.e., Tonani et al., 2008; Beranger et al., 2005) but none of them has demonstrated the sensitivity of the simulated Mediterranean circulation to the coupling with the Atlantic.

Mediterranean circulation is forced by water exchanges through the Gibraltar and Dardanelles Straits, by wind stress and by large freshwater fluxes and intense winter heat fluxes. The general characteristics of the basin circulation and forcing have been overviewed recently by Pinardi et al. (2006). In a very schematic way, the Mediterranean Sea thermohaline circulation can be described as a large scale anti-estuarine buoyancy-driven circulation with fresher surface waters inflow and subsurface saline waters outflow at Gibraltar. The relatively fresh water from the Atlantic flows through the Strait of Gibraltar and becomes Modified Atlantic Water (MAW) due to intense air-sea exchanges with the atmosphere. The MAW, crossing the Strait of Sicily, reaches the eastern basin and ends up in the Levantine. Here, cooling in winter causes convection to intermediate depths (up to $500 \mathrm{~m}$ ) mainly in the Rhodes gyre forming Levantine Intermediate Water (LIW, Lascaratos et al., 1993). The Levantine Intermediate Water, characterized by a salinity and temperature maxima between 200 and $500 \mathrm{~m}$ depth, forms

Published by Copernicus Publications on behalf of the European Geosciences Union. 


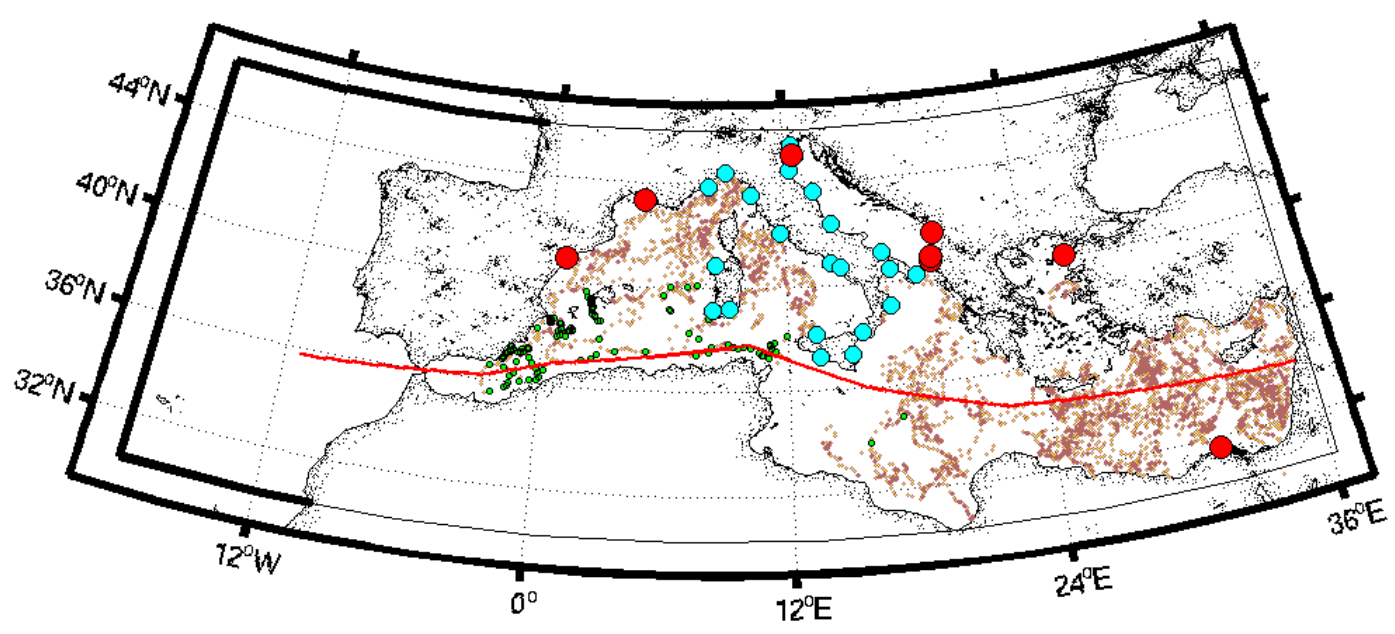

Fig. 1. Model domain. Bold lines in the Atlantic indicate location of model lateral boundaries. Red circles indicate river locations and the Dardanelles inflow. Dots (red and dark green) indicate ARGO float positions. The dark green dots indicate position of the ARGO floats sampling the inflowing Atlantic Water. Cyan dots indicate the position of tide gauges. Red line indicates the cross section shown in Fig. 4.

the main component of the Mediterranean outflow to the Atlantic. LIW also provides a preconditioning mechanism for the Eastern Mediterranean Deep Water (EMDW) and the Western Mediterranean Deep Water (WMDW), the two locally formed deep waters of the basin.

Moreover, the horizontal circulation structure is rather complex, consisting of mesoscale and sub-basin scale gyre structures. Permanent, recurrent and transitional cyclonic and anticyclonic gyres and eddies, influenced by bathymetric features are interconnected by currents and jets (Robinson et al., 1994; Pinardi et al., 2006). The complexity of the circulation is due to the special combination of the surface forcing with the lateral fluxes imposed by water exchanges at the Gibraltar Strait. It is therefore important to show the sensitivity of the circulation to the Atlantic-Mediterranean coupling and two approaches are compared in this paper. The first consists of a consolidated modelling approach (Roussenov et al., 1995; Demirov and Pinardi, 2002; Tonani et al., 2008) where a large Atlantic box is considered with closed boundaries and relaxation to climatology for the temperature and salinity tracers. Gibraltar is explicitly resolved by the model but the Atlantic is heavily parameterized. The second consists of one-way, state-of-the-art nesting of a limited area general circulation model in a global scale model (Marchesiello et al., 2001; Oddo and Pinardi, 2008). Other approaches have been used in the past, most of them use a limited buffer zone in the Atlantic where temperature and salinity are relaxed to seasonal data, observation- or model-derived (Beranger et al., 2005; Testor et al., 2005; Bozec et al., 2006). The final objective of this paper is to show how two different Atlantic-Mediterranean coupling methods influence the Mediterranean Sea circulation.

Section 2 describes the general circulation model implementation. Model results and comparison with observations are discussed in Sects. 3 and 4. Section 5 offers summary and conclusions.

\section{Ocean model description}

The present Mediterranean operational model, hereafter called MFS_V1, is an implicit free-surface version of the Ocean PArallelise code (OPA, Madec et al., 1998) with a $1 / 16^{\circ}$-degree horizontal regular resolution and 72 unevenly spaced vertical z-levels (Tonani et al., 2008). In this paper we describe a new model implementation carried out with the same horizontal and vertical regional boundaries but based on a new OPA code (OPA 9.0 Madec, 2008), hereafter called MFS_V2. Only the differences with the earlier system will be described here in any detail.

MFS_V2 covers the entire Mediterranean Sea and also extends into the Atlantic (see Fig. 1) with the same horizontal and vertical resolution of MFS_V1. However, MFS_V2 uses vertical partial cells to fit the bottom depth shape. Like MFS_V1, the model is forced by momentum, water and heat fluxes interactively computed by bulk formulae using the 6-h, $0.5^{\circ}$ horizontal-resolution operational analyses from the European Centre for Medium-Range Weather Forecasts (ECMWF) and model predicted surface temperatures (details of the air-sea physics are in Tonani et al., 2008). The only difference in the bulk formula concerns the calculation of the latent heat flux; in the previous model implementation constant turbulent exchange coefficients were used, while in the model presented here they vary according to the empiric formula suggested by Kondo (1975).

One difference with the earlier version of the system regards surface water and salt fluxes. In this model we use the 
natural surface boundary condition for vertical velocity:

$$
w\left|z=h-\left(\frac{\partial h}{\partial t}+\bar{v} \cdot \nabla h\right)\right|_{z=h}=-\left(E-P-\frac{R}{F_{R}}\right)
$$

where $w$ is the vertical velocity, $h$ is the surface elevation, $E$ is the evaporation in $\mathrm{m} \mathrm{s}^{-1}, P$ is the precipitation in $\mathrm{m} \mathrm{s}^{-1}, R$ indicates the rivers runoff in $\mathrm{m}^{3} \mathrm{~s}^{-1}$ and $F_{R}$ the river mouth discharge area. The complementary salt flux boundary condition is also:

$$
\left.A_{k} \frac{\partial S}{\partial z}\right|_{z=h}=S_{z=h}\left(E-P-\frac{R}{F_{R}}\right)
$$

where $A_{k}$ is the vertical turbulent diffusion coefficient in $\mathrm{m}^{2} \mathrm{~s}^{-1}$ and $S_{z=h}$ is the model surface salinity in PSU. In MFS_V1 the water flux, $\left(E-P-\frac{R}{F_{R}}\right)$, was estimated by means of a relaxation to surface climatological salinity (Tonani et al., 2008). In MFS_V2, $E$ is derived from the latent heat flux; $P$ is taken from monthly mean Climate Prediction Center Merged Analysis of Precipitation (CMAP) Data (Xie and Arkin, 1997) and $R$ is composed of monthly mean climatological data. Only seven major rivers have been implemented (Fig. 1): the Ebro, Nile and Rhone monthly values are from the Global Runoff Data Centre (Fekete et al., 1999) and the Adriatic rivers (Po, Vjosë, Seman and Bojana) are from Raicich (Raicich, 1996). In this model configuration the Dardanelles inflow has been parameterized as a river and its monthly climatological net inflow rates were taken from Kourafalou and Barbopoulos (2003).

The advection scheme for active tracers (temperature and salinity) has been modified, replacing the 2nd order centered advection (MFS_V1) with a mixed up-stream/MUSCL (Monotonic Upwind Scheme for Conservation Laws, Van Leer, 1979, as implemented by Estubier and Lévy, 2000) scheme. This flux-limiting scheme is particularly suitable for operational purposes not only because it is able to preserve gradients without significant numerical noise, but also because it has the capability to switch, without additional computational cost, to a simple up-stream scheme in areas where numerical instabilities can occur. The up-stream scheme is used in proximity of the river mouths, in the Gibraltar Strait and close to the Atlantic lateral boundaries. This "diffusive" advection scheme is used to simulate a "sponge layer" in order to avoid numerical overshooting due to large horizontal and/or vertical gradients deriving from the fresh water runoff and to numerical discontinuities due to the only partially exact imposition of lateral boundary conditions. At Gibraltar, the up-stream scheme, together with an artificially increased vertical diffusivity (similar to MFS_V1 implementation), parameterizes the large mixing acting in this area due to the internal wave and tide breaking, which is not explicitly resolved by the model (tidal dynamics is not implemented in both MFS_V1 and MFS_V2).

The major model improvement discussed in this paper concerns the parameterization of the connection between the Mediterranean Sea and the North Atlantic Ocean. In MFS_V1, the Atlantic part of the model consisted of three closed boundaries where, in order to keep the solution realistic, the temperature and salinity were relaxed toward monthly climatological values (Levitus, 1998) using a space dependent relaxation function. In the same area a sponge layer was also implemented in order to reduce the numerical noise (Tonani et al., 2008). In MFS_V2, the Atlantic box is nested within the monthly mean climatological fields computed from the daily output of the $1 / 4 \times 1 / 4$ degrees global model, hereafter called MERCATOR-1/4 (Drevillon et al., 2008), spanning from 2001 to 2005.

In order to understand and quantify the improvements deriving from the nested approach better, two different implementations of the new model are considered in this study: in the first (MFS_V2.1) the same parameterization as MFS_V1 has been adopted in the Atlantic area; in the second (MFS_V2.2) the model has been nested into the global model using a lateral open boundary condition approach.

In the MFS_V2.2 model, the 2-D adaptive radiation condition (Marchesiello et al., 2001; Oddo and Pinardi, 2008) has been used for the active tracers. Total velocities at the open boundaries are imposed from the global model solution, while barotropic velocities use a modified Flather (1976) lateral boundary condition explained in Oddo and Pinardi (2008). The nested normal total velocity, $u$, imposed at the lateral open boundaries, is:

$u=u^{\mathrm{ext}}-\overline{u^{\mathrm{ext}}}\left(1-\frac{H+\eta^{\mathrm{ext}}}{H+\eta}\right)+\frac{C}{H+\eta}\left(\eta-\eta^{\mathrm{ext}}\right)$

where $u^{\text {ext }}$ and $\eta^{\text {ext }}$ are the total velocity and the surface elevation prescribed by the nesting global model respectively, $C$ is the phase velocity calculated using an Orlanski formulation (Orlanski, 1976), $\eta$ is the nested model free surface and $\overline{u^{\text {ext }}}$ is the vertically integrated (barotropic) velocity defined as follows:

$\overline{u^{\mathrm{ext}}}=\frac{1}{H+\eta^{\mathrm{ext}}} \int_{-H}^{\eta^{\mathrm{ext}}} u^{\mathrm{ext}} d z$.

Using a closed domain model (MFS_V2.1), particular attention should be given to volume conservation in the presence of the natural vertical boundary condition (1). Here we use the same approach described in Tonani et al. (2008) to correct the surface water flux in the Atlantic-Mediterranean closed model domain. The model surface mean of the water flux, $\left(E-P-\frac{R}{F_{R}}\right)$, is subdivided into two parts, the Atlantic and the Mediterranean, and at each time step the surface integral of the water flux over the two areas is computed. A new value for the water flux over the Atlantic is computed in order to have the net water flux equal zero over the whole domain and preserve the model volume. Differences between MFS_V1, MFS_V2.1 and MFS_V2.2 are summarized in Table 1. 
Table 1. Major differences between the previous Mediterranean Forecasting System (MFS) model implementation and the two new versions analyzed in this study: MFSV2.1, closed domain ; MFS_V2.2 open domain.

\begin{tabular}{|c|c|c|c|}
\hline Vertical discretization & $\begin{array}{l}\text { MFS_V1 } \\
\text { z-levels }\end{array}$ & $\begin{array}{l}\text { MFS_V2.1 } \\
\text { z-levels + partial cells }\end{array}$ & $\begin{array}{l}\text { MFS_V2.2 } \\
\text { z-levels + partial cells }\end{array}$ \\
\hline $\begin{array}{l}\text { (Evaporation - } \\
\text { Precipitation - } \\
\text { Runoff) }\end{array}$ & Relaxation to surface salinity clim & $\begin{array}{l}\text { Interactively computed } \\
\text { CMAP precipitation } \\
\text { Clim runoff }\end{array}$ & $\begin{array}{l}\text { Interactively computed } \\
\text { CMAP precipitation } \\
\text { Clim runoff }\end{array}$ \\
\hline Tracer advection & 2nd order centred & MUSCL + up-stream & MUSCL + up-stream \\
\hline Lateral boundaries & Closed + relaxation to Levitus Clim & $\begin{array}{l}\text { Closed + relax to MERCA- } \\
\text { TOR }\end{array}$ & $\begin{array}{l}\text { Open - nested with MER- } \\
\text { CATOR }\end{array}$ \\
\hline
\end{tabular}

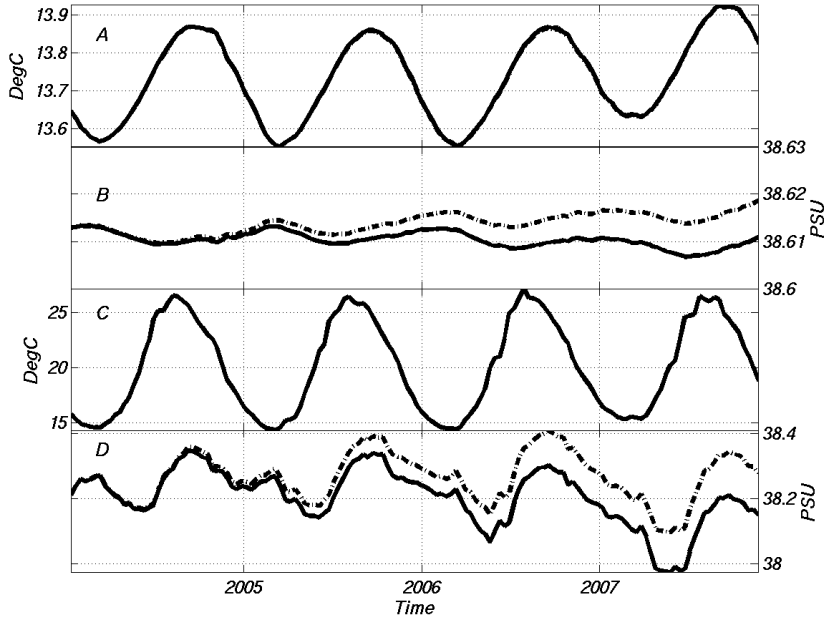

Fig. 2. (A) Time series of mean volume temperature. Solid (MFS_V2.1) and dashed (MFS_V2.2) lines overlap. (B) Time series of mean volume salinity, solid line indicates MFS_V2.1 results, dashed line indicates MFS_V2.2 results. (C) Time series of mean surface temperature, solid line (MFS_V2.1) and dashed (MFS_V2.2) lines overlap. (D) Time series of mean surface salinity, solid line indicates MFS_V2.1 results, dashed line indicated MFS_V2.2 results.

The simulations started from climatological temperature and salinity fields on 1 January 2004 and ended on 31 December 2007.

\section{The Atlantic influence on the Mediterranean Sea}

In this section we compare the results of MFS_V2.1 and MFS_V2.2 for different state variable average values. The differences will highlight the influence of the full Atlantic dynamics on Mediterranean Sea variability.

In Fig. 2 MFS_V2.1 and MFS_V2.2 temperature and salinity volume and surface Mediterranean averages are shown. The time series of volume (Fig. 2a) and surface (Fig. 2c) averaged temperature of the two model simulations overlap,
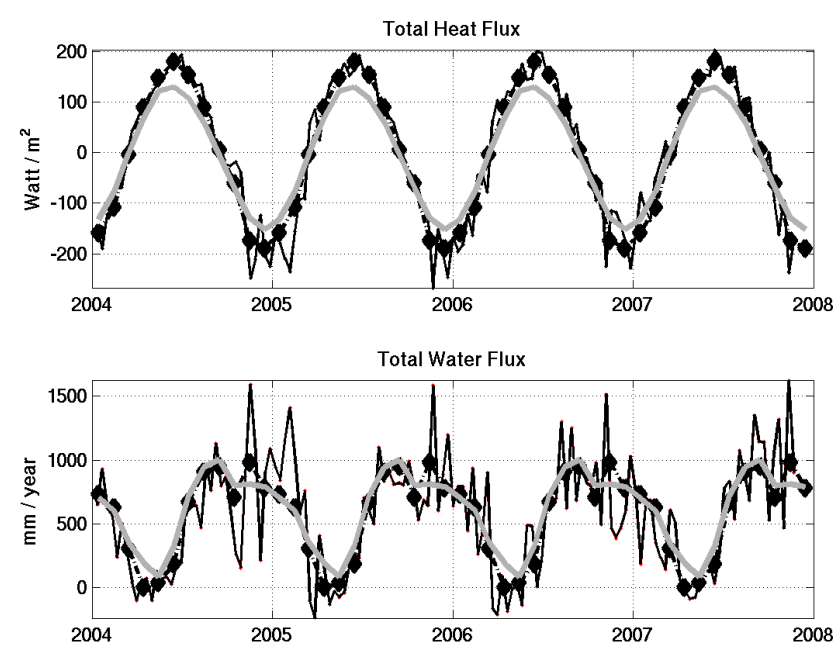

Fig. 3. Top panel: Time series of Total Heat Flux. The grey line indicates climatology from NCEP; solid markers indicate models climatology (averaging 4-years run); solid thin line indicates 10-day average inter-annual values from model simulations. Bottom panel: Time series of Total Water flux (E-P-R). The grey line indicates climatology from Mariotti et al. (2002); solid markers indicate models climatology (averaging 4-years run); solid thin line indicates 10day average inter-annual values from model simulations. In both panels, climatological and inter-annual values from MFS_V2.1 and MFS_V2.2 overlap.

indicating that the Mediterranean average temperature is not affected by lateral open boundary conditions in the Atlantic. Analyzing volume (Fig. 2b) and surface (Fig. 2d) mean salinity, differences are evident, however. The two time series diverge and a freshening in the MFS_V2.1 solution is observed. The volume averaged salinity differences between MFS_V2.1 and MFS_V2.2 are small, after 4 years the difference is less than $0.006 \mathrm{psu}$ while the two surface averaged salinity fields differ by about $0.2 \mathrm{psu}$. The reason for this is clearly connected to the different proprieties of the inflowing Atlantic waters, which are due to the volume preserving factor applied in MFS_V2.1, as explained below. 

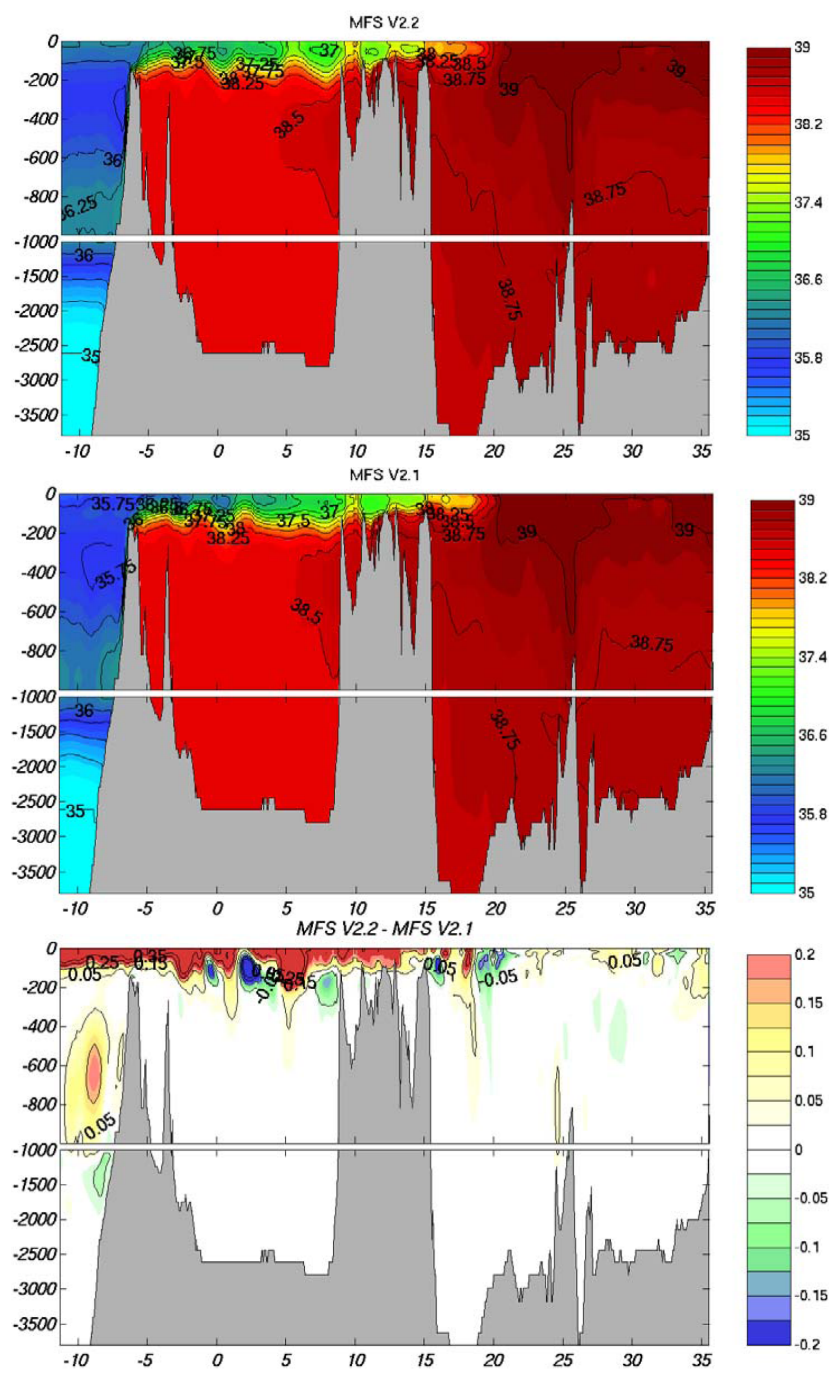

Fig. 4. Salinity cross section along the track shown in Fig. 1. Bottom panel: difference between MFS_V2.2 and MFS_V2.1. The fields are the yearly mean for 2007.

In Fig. 3 the surface mean heat and water surface fluxes over the Mediterranean region are shown. The time series of the two simulations almost overlap, indicating that the surface fluxes over the Mediterranean region are not influenced by lateral boundary condition parameterizations in the Atlantic. Moreover, the estimated surface fluxes (Fig. 3), are in good agreement with analysed climatological values, as deduced from NCEP 40 years re-analysis (Kistler et al., 2001). The only remarkable difference between simulated and observed values regards the amplitude of the seasonal cycle and we argue that this is due to the different length of the timeseries used to compute climatologies (4 years for MFS and 40 years for NCEP).

Salinity vertical fields along the section crossing the whole Mediterranean Sea (red line in Fig. 1) are shown in Fig. 4
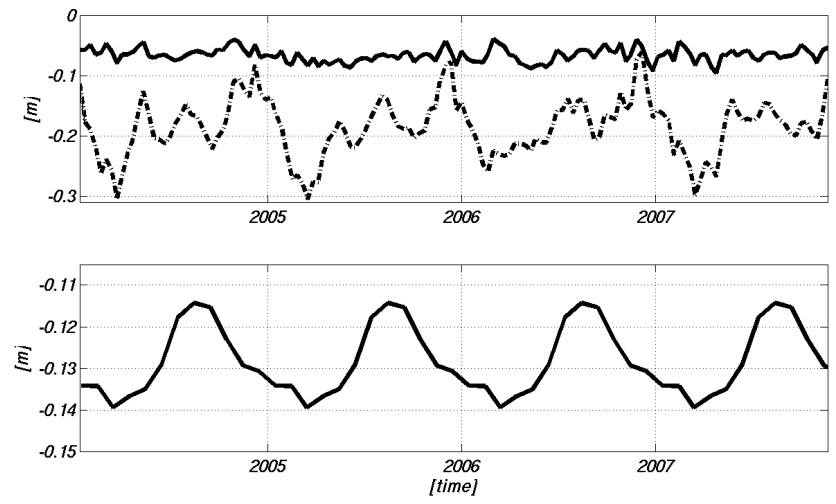

Fig. 5. Top panel: Time series of Mediterranean Sea mean surface elevation from MFS_V2.1 (solid line) and MFS_V2.2 (dashed line) simulations. Bottom panel: Time series of mean surface elevation along the open boundaries from global model.

for both models together with their differences (Fig. 4 bottom panel); the fields shown are the 2007 yearly mean. In both model solutions the inflowing Atlantic water layer is evident between $6^{\circ} \mathrm{W}$ and $18^{\circ} \mathrm{E}$. Moreover, in agreement with the previous analyses, MFS_V2.2 has higher Atlantic water salinity values at the surface. The increased salt content of the incoming Atlantic waters is not sufficient to strongly modify the stability of the water column. In the Atlantic side, the vertical stability is ensured by the combination of the large temperature gradient, the effect of the pressure and the salty Mediterranean outflow. In the Mediterranean Sea, where vertical gradients of temperature are less pronounced, the saltier Atlantic waters simulated by MFS_V2.2 are still fresh enough to be buoyant. In the Western Mediterranean Sea some negative difference areas are observed below the intruding Atlantic waters, indicating that MFS_V2.2 has patches of lower salinity than MFS_V2.1. This is due to the different eddy dynamics in the area of the Algerian current, which results in a displacement of the eddies and jets. It is also interesting to note that the Mediterranean outflow in MFS_V2.2 is saltier than in MFS_V2.1.

In Fig. 5 (top panel) the time-series of the surface elevation averaged over the Mediterranean Sea from MFS_V2.1 and MFS_V2.2 are shown. For this quantity, the differences between the two simulations are very large. In the closed domain a month-to-month variability is observed without a clear seasonal cycle; the amplitude of the oscillations is less than $5 \mathrm{~cm}$ and the multiyear mean Mediterranean sea level is centred at about $-6.5 \mathrm{~cm}$. In the MFS_V2.2 simulation, a clear seasonal cycle is observed having two to three different maxima during the year. The absolute annual maximum is reached in early December, while the other maxima appear in spring (May) and summer (August); the minimum value in all the simulated years occurs in March. The amplitude of the seasonal variations is about $20 \mathrm{~cm}$ (in agreement with previous observational studies, i.e., Fukumori et al., 2007) 

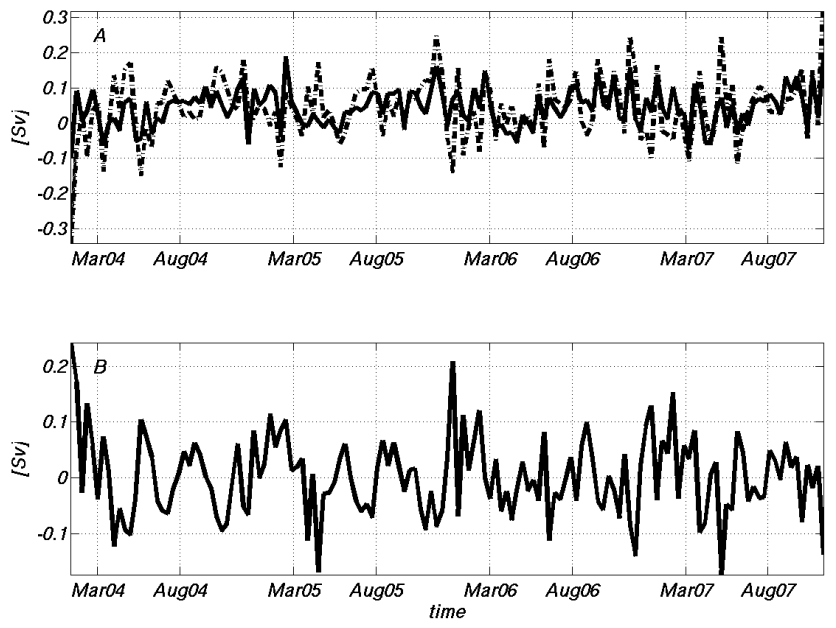

Fig. 6. (A) time-series of net volume transport at Gibraltar Strait, solid line indicate MFS_V2.1 results, dashed line indicates MFS_V2.2 results. (B) time-series differences of net volume transport at Gibraltar between the two model simulations.

and the multiyear averaged Mediterranean sea level is about $-18 \mathrm{~cm}$.

The global model sea level averaged along the lateral open boundaries (Fig. 5, bottom panel) shows a seasonal oscillation of about $3 \mathrm{~cm}$ connected to the Atlantic open ocean wind response. The minima in the North Atlantic mean surface elevation coincide with the Mediterranean yearly absolute minima (March), while some of the yearly maxima of the Atlantic and Mediterranean time series occur at different times.

The mean surface elevation changes are driven by surface fluxes and the Gibraltar inflow. Taking the Mediterranean area average of Eq. (1) we obtain the time evolution equation for the surface average sea level, $\langle\eta\rangle$ :

$\frac{\partial\langle\eta\rangle}{\partial t}=\frac{\mathrm{Gib}}{A_{\mathrm{med}}}-\left\langle E-P-\frac{R}{F_{R}}\right\rangle$.

Where Gib is the net transport at Gibraltar $\left(\mathrm{m}^{3} / \mathrm{s}\right), A_{\text {med }}$ is the area of the Mediterranean Sea, and the 2nd term in the r.h.s. of the Eq. (4) is the Mediterranean average surface water flux. As shown in Fig. 3, the area average surface water flux does not differ between MFS_V2.1 and MFS_V2.2, thus the differences in mean sea level oscillations, shown in Fig. 5, are due to the transport at Gibraltar. In particular, assuming steady state in Eq. (4) the net transport value for Gib is $0.05 \mathrm{~Sv}$, consistent with recent observations and calculations (Menemenlis et al., 2007).

In Fig. 6a the time series of net mass transport through the Gibraltar Strait is shown. Both MFS_V2.1 and MFS_V2.2 time series have a time mean average of $4 \times 10^{-2} \mathrm{~Sv}$ but MFS_V2.2 is characterized by larger oscillations. The differences between the two simulations (Fig. 6b) have a seasonal cycle, with marked inter-annual variability, and the values can be as large as the average net transport. MFS_V2.1 has larger transport during early winter (January, February) and summer (August, September) while MFS_V2.1 has smaller transport in spring (April, May) and fall (October). We can conclude that the differences induced in the Atlantic box produce different net transports at Gibraltar, which in turn induce mean sea level variations at the seasonal and interannual time scales. These fluctuations are clearly removed in the closed Atlantic box model case.

In order to understand whether the Atlantic influence on the Mediterranean Sea water mass structure and sea level is a real improvement, we will compare the two simulations with observations.

\section{Quality assessment of the simulations}

In this section we compare the simulations with observations deriving from ARGO floats (Poulain et al., 2007), satellite and tide gauge sea level.

The evaluation is done by means of standard statistics indexes such as Root-Mean-Square-Error (RMSE), Mean Error (ME) and pattern correlation coefficient (PCC), and the comparison is presented in terms of a Relative Performance (RP) index. The RP has been defined as:

$R P=\left(1-\frac{S T_{V 2.2}}{S T_{V 2.1}}\right) * 100$

where $S T_{V 2}$ indicates the computed statistics (RMSE, ME or PCC) of MFS_V2.1 and MFS_V2.2. The PCC has been computed on the anomalies, subtracting the corresponding climatological mean profile for each dataset. The PCC has been also computed subtracting the same climatological profiles from both observations and model results (not shown), the results obtained with this method are very similar to the one presented in the following section. RP values $>0$ in Eq. (5) indicate an improvement (MFS_V2.2 better than MFS_V2.1) while RP values $<0$ show a deterioration. For PCC, the ratio of MFS_V2.1 and MFS_V2.2 is inverted in Eq. (5) in order to maintain the same interpretation of the index values. For instance, $\mathrm{RP}=50 \%$ means that the model error (RMSE, ME or PCC) has been reduced to half of its reference value, while $\mathrm{RP}=-100 \%$ indicates that the error in the MFS_V2.2 is double respect to MFS_V2.1. All the statistics considered have been averaged horizontally and temporally.

\subsection{The temperature and salinity water mass properties}

In Fig. 7a, b, c salinity and temperature RMSE, ME and PCC are shown for differences between ARGO profiles (shown in Fig. 1) and MFS_V2.2.

Salinity RMSE (Fig. 7a, red line) is maximum at the surface with a value of about $0.28 \mathrm{psu}$ and rapidly decreases toward the bottom stabilizing at about 0.007 around $300 \mathrm{~m}$ depth. Temperature RMSE (Fig. 7a, dark line) has a subsurface maximum, close to $1^{\circ} \mathrm{C}$, related to the error of reproduction of the seasonal thermocline. Temperature and 
['C]
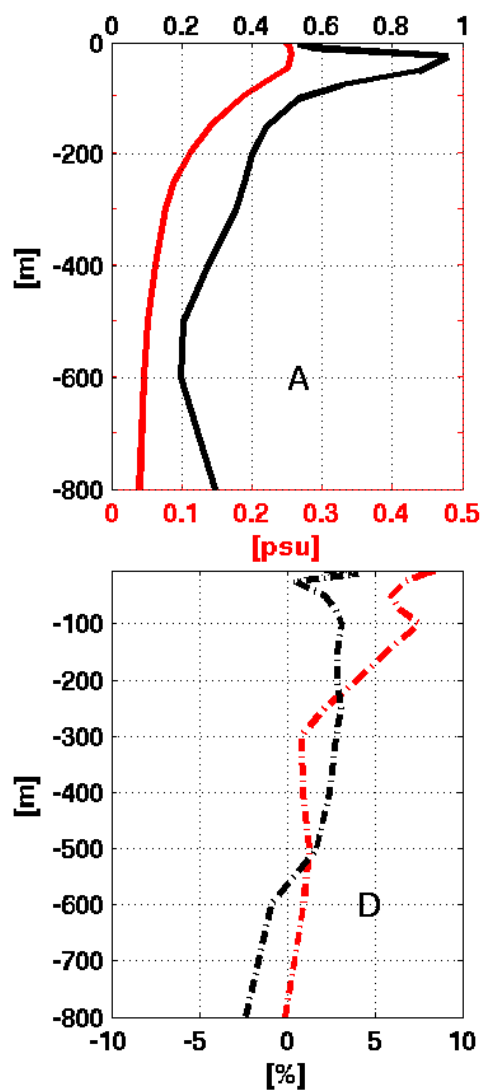

['C]
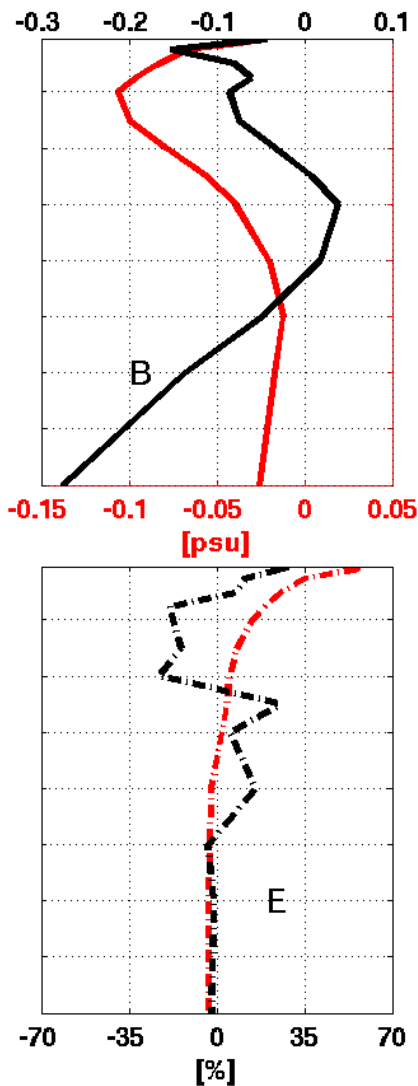
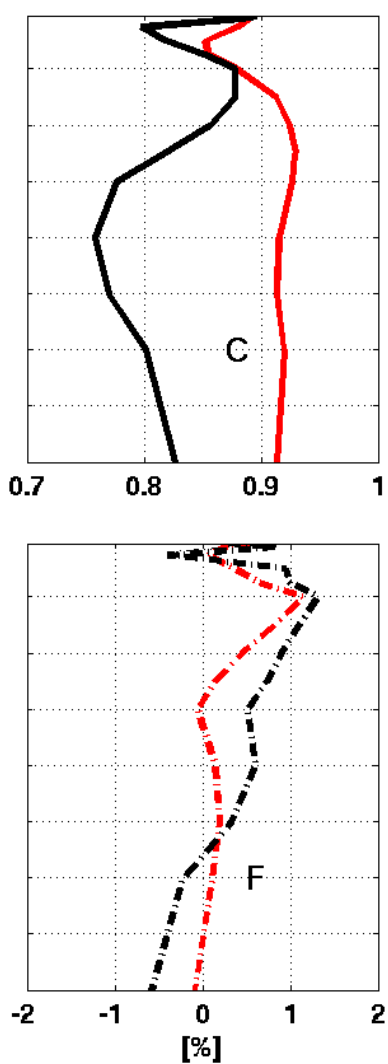

Fig. 7. Upper panels: Temperature and Salinity RMSE (A), ME (B) and pattern correlation coefficient (C) vertical profiles for MFS_V2.1. Bottom panels: RP vertical profiles for RMSE (D) ME (E) and pattern correlation coefficient (F). Black lines indicate Temperature, red lines indicate salinity data.

salinity ME (Fig. 7b) are both negative indicating that the model underestimates salinity and heat content; moreover, the two curves have different shapes. In fact, the salinity ME has a sub-surface maximum located at $100 \mathrm{~m}$ depth, while temperature biases are larger near the bottom. Both temperature and salinity have high PCC values ranging between 0.75 and 0.95 ; moreover, temperature PCC has a minimum at $400 \mathrm{~m}$ depth, while salinity has it at $80 \mathrm{~m}$ depth. Results for MFS_V2.1 are compared in terms of RP (bottom panels in Fig. 7) for each of the considered statistics. The temperature and salinity RP for RMSE are both positive, indicating that MFS_V2.2 has greater skill than MFS_V2.1. Moreover, the improvements in RMSE deriving from MFS_V2.2 are mostly confined at the surface both for temperature (Fig. 7d dark line) and salinity (Fig. 7d, red line). The largest improvement is observed for salinity with RP values between 8 and $9 \%$, while for temperature they are less than $5 \%$, and a deterioration of the solution is observed below $600 \mathrm{~m}$ depth, even if small (less than 2\%). The most relevant differences between MFS_V2.1 and MFS_V2.2 concern the salinity ME (Fig. 7e). The RP for ME also has maximum values at the surface and, in this case too, MFS_V2.2 seems to repre- sent the salinity and temperature of the surface water better (dashed line RP $>50 \%$ for salinity and RP $>20 \%$ for temperature). A worsening of temperature ME is observed between 100 and $200 \mathrm{~m}$ depth, with values close to $20 \%$ but, at these depths, both the model configurations have a small bias value, close to $-0.05^{\circ} \mathrm{C}$.

The differences in PCC (Fig. 7f) are smaller than the other considered statistics, but for this indicator too MFS_V2.2 has a greater skill for both temperature and salinity, with a maximum between 100 and $200 \mathrm{~m}$ depth indicating an improvement in the reproduction of the mixed layer depth. Since PCC is an indicator of model performance in reproducing mesoscale activities, the small differences between the two simulations can be due to the fact the small scale features are locally formed and do not depend on the lateral boundary condition parameterization.

The slight deterioration of the MFS_V2.2 solutions in the deeper layer could be related to the vertical mixing parameterization, which maybe requires further tuning, having a better reproduction of the water masses characteristics.

In Fig. 8 the mean temperature (A) and salinity (B) of the Atlantic water entering into the Mediterranean at the 

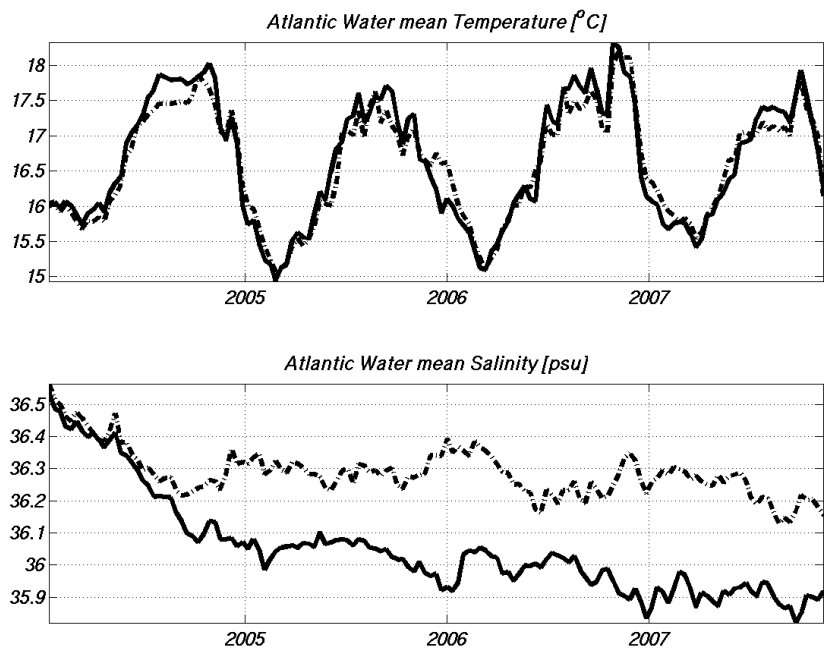

Fig. 8. Top panel: Time series of inflowing Atlantic water averaged Temperature from MFS_V2.1 (solid line) and MFS_V2.2 (dashed line). Bottom panel: Time series of inflowing Atlantic water averaged Salinity from MFS_V2.1 (solid line) and MFS_V2.2 (dashed line).

Gibraltar Strait are shown. The mean temperatures (Fig. 8a) of the Atlantic water are very similar, with a clear and strong seasonal cycle. This is due to the fact that the Atlantic waters entering into the Mediterranean Sea are surface waters and the air-sea fluxes totally determine their temperature. However the amount of the inflowing Atlantic water is different between the two simulations (Fig. 6), thus the water masses can be differently advected producing the small differences in temperature observed within the Mediterranean Sea (Fig. 7).

On the contrary, the entering water has very different salt content in the two simulations (Fig. 8b). In the closed domain simulation the mean salinity of the Atlantic water decreases with time while in MFS_V2.2 after the first year of integration its values remain about constant with seasonal modulations. This is due to the fact the water (and salinity) surface fluxes in the two model implementations are different, in the Atlantic area, by the volume preserving correction factor. The correction factor performed to preserve the volume in the closed simulation produces on average a dilution of the surface Atlantic waters.

In order to have an estimate of the quality of the simulated Atlantic waters salinity, we compare model results with various ARGO buoys extracted, on the base of geographic location and surface salinity, from the entire data-set (green dots in Fig. 1). The intent of this sub-sampling is to filter out other water masses in the observations. A sub-sampling based only on the geographic locations was not sufficient due to the very complex Alboran Sea surface circulation with a number of gyres, eddies and jet. In Fig. 9 mean salinity profiles from observations and models are shown together with the corresponding RMSE and ME RP indexes.
Both models underestimate surface salinity (from 0 to $300 \mathrm{~m}$ depth), but the MFS_V2.2 configuration has strongly reduced this bias, especially in the first $30 \mathrm{~m}$ of the water column. The RP for RMSE at the surface is larger than $20 \%$ and it decreases going downward; below $150 \mathrm{~m}$ depth a worsening of the solution is observed but at this depth the models errors are very small (0.02 psu). Larger improvements, deriving from the MFS_V2.2 model configuration, are observed in the salinity ME. RP values at surface are close to $60 \%$ indicating that the bias, from MFS_V2.1 to MFS_V2.2, has halved.

In synthesis, MFS_V2.2 generally captures better the salinity of the inflowing Atlantic water. We believe this is due to the freshening effect of the water flux volume preserving corrections discussed in Sect. 2 required by the closed model domain in the Atlantic. This behaviour was alleviated in the previous operational model implementation (MFS_V1) since the water flux $\left(E-P-\frac{R}{F_{R}}\right)$ was computed relaxing to surface climatological salinity.

\subsection{Surface elevation seasonal oscillation}

In this section we would like to show that the Mediterranean seasonal mean sea level oscillations from MFS_V2.2, shown in Fig. 5, compare better with observations than MFS_V2.1. To do this, we compare the model simulated sea surface elevations with the corresponding field obtained from altimetry sea level and tide gauges. The altimeter products (Sea Level Anomaly, SLA) were produced by Ssalto/Duacs and distributed by Aviso, with support from CNES; in particular we used Envisat and Jason-1 along-track satellite sea level anomaly data (see Pujol and Larnicol, 2005, for details). The tide gauge data have been provided by the Italian Agency for Environmental Protection.

Following Mellor and Ezer (1995) and Greatbatch (1994), sea level in a Boussinesq, incompressible, model like ours needs to have the steric effect added before it can be compared with observations. The importance of the steric effect in the observed record is discussed in Cazenave et al. (1998). In order to take into account the non-Boussinesq effects in our model results, vertical and horizontal means of the model density profiles have been computed for each day of the simulations and added to the model sea level. Mellor and Ezer (1995) show that this is enough to restore the full sea level variability of a non-Boussinesq model.

The mean dynamic topography for the model simulations have been computed averaging the surface elevation over the entire integration period. In Fig. 10a the time series of the mean sea level anomalies from satellite altimetry and both MFS_V2.1 and MFS_V2.2 are shown. In order to compare the model and the observations, the former has been sampled at the observational points and then the difference computed; the latter is averaged along-track over the same time window of the model output. 

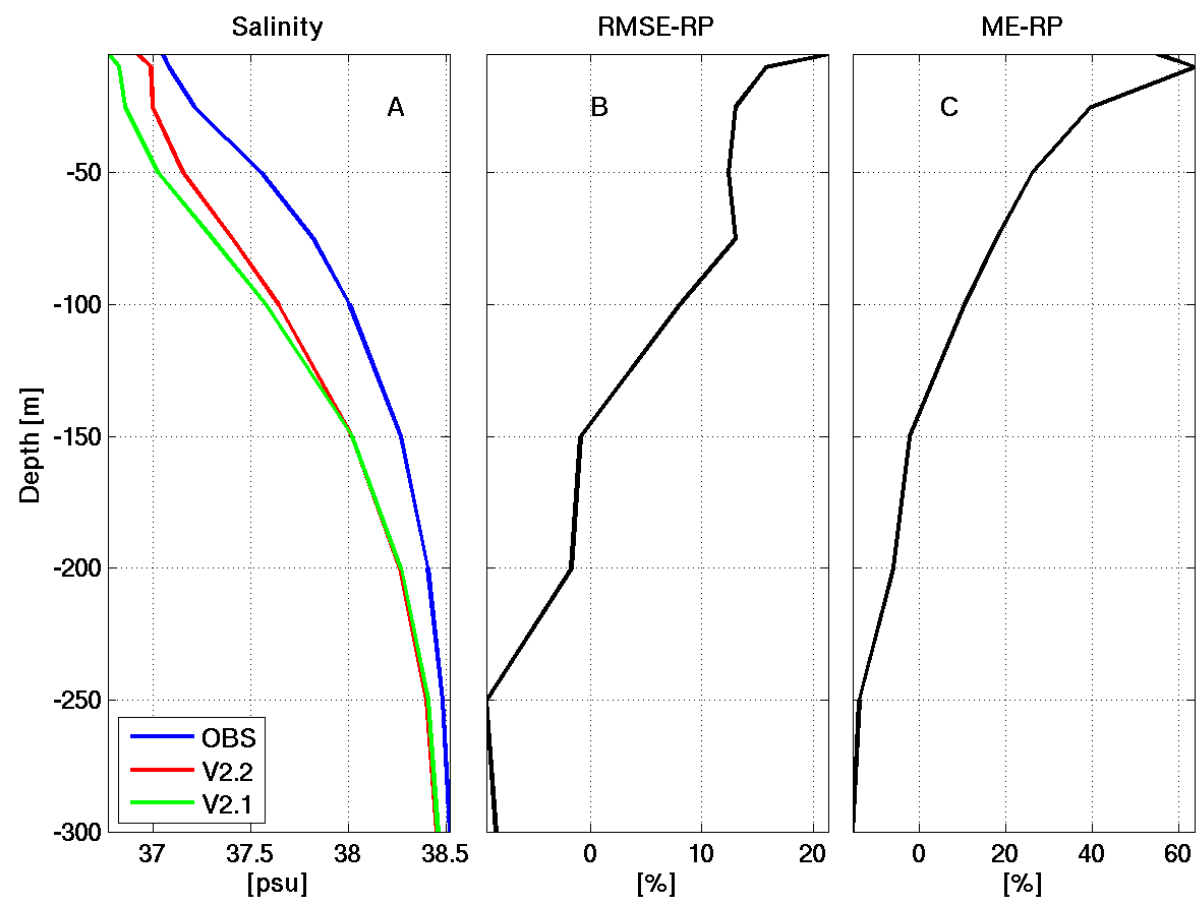

Fig. 9. (A) vertical profiles of salinity, obtained averaging observations and model data in the green dots shown in Fig. 1. Blue line indicates observations (ARGO floats), green line indicate MFS_V2.1 results and red line indicates MFS_V2.2 results. Relative performance index for salinity for RMSE (B) and mean-error (C).

It is clear that MFS_V2.2 better reproduces the amplitude and the shape of the observed seasonal cycle, while MFS_V2.1 strongly underestimates the observed seasonal variability.

One of the most interesting features captured by the interaction with the Atlantic in the MFS_V2.2 model is the summer-autumn maxima. In fact, both the satellite and model (MFS_V2.2) time series are characterized by double maxima; the first occurring in August and the second in November-December. Some differences between MFS_V2.1 solution and satellite-derived observations are still present, and are mostly due to the correct reproduction of the inter-annual variability. The summer maximum, as discussed before, is also observed in the global model solution; we thus argue that this large scale induced processes. The other maxima are due to local (Mediterranean) processes that in the nested simulation are free to develop while in the closed simulation are suppressed.

In order to better understand the differences and similarities between simulated and observed surface elevation, the power spectrum of the three time-series is shown in Fig. 10b.

For all the considered datasets the spectrum is discontinuous and characterized by well marked maxima. In the satellite observations $42 \%$ of the total variance $\left(0.45 \mathrm{~m}^{2}\right)$ is explained by the first 3 dominant frequencies corresponding at 12,4 and 6 months $^{-1}$ and having energies of 0.17 (38\%), $0.011(2.5 \%)$ and $0.004 \mathrm{~m}^{2}(0.8 \%)$ respectively. MFS_V2.2 has comparable energy content $\left(0.49 \mathrm{~m}^{2}\right)$ but distributed in a different way: the $12-$ month $^{-1}$ oscillation energy is about $0.14 \mathrm{~m}^{2}$ (corresponding to $30 \%$ of the total); the energy associated with the $6-$ month $^{-1}$ frequency is $0.035 \mathrm{~m}^{2}(7 \%)$ and the $4-$ month $^{-1}$ frequency has $0.014 \mathrm{~m}^{2}$ associated energy $(2.8 \%)$. The total variance in the MFS_V2.1 simulation is $0.08 \mathrm{~m}^{2}$, significantly smaller than the observed value; $37 \%$ $\left(0.03 \mathrm{~m}^{2}\right)$ of this variance is due to an oscillation with frequency of 12 months $^{-1}$; the residual part is distributed homogeneously in the remaining frequencies.

In addition, it is interesting to note that at higher frequencies (Fig. 10b2), satellite and MFS_V2.2 power spectra are similar (MFS_V2.2 has the right variance at the right frequencies), while MFS_V2.1 also underestimates the amplitude of the signal at these scales.

The reconstructed signals from both observation and model results are shown in Fig. 10c and d. In panel (c) the signals have been reconstructed using only the first three dominant frequencies for each dataset (different frequencies have been considered for different dataset); in panel (d) the surface elevation has been reconstructed filtering out the frequencies used for the previous panel. The double maximum simulated by MFS_V2.2 implementation is now also more evident in the observations, even though it is characterized by a strong inter-annual variability, while the major difference between simulated and observed values are the relative maxima observed in February. The differences between model 

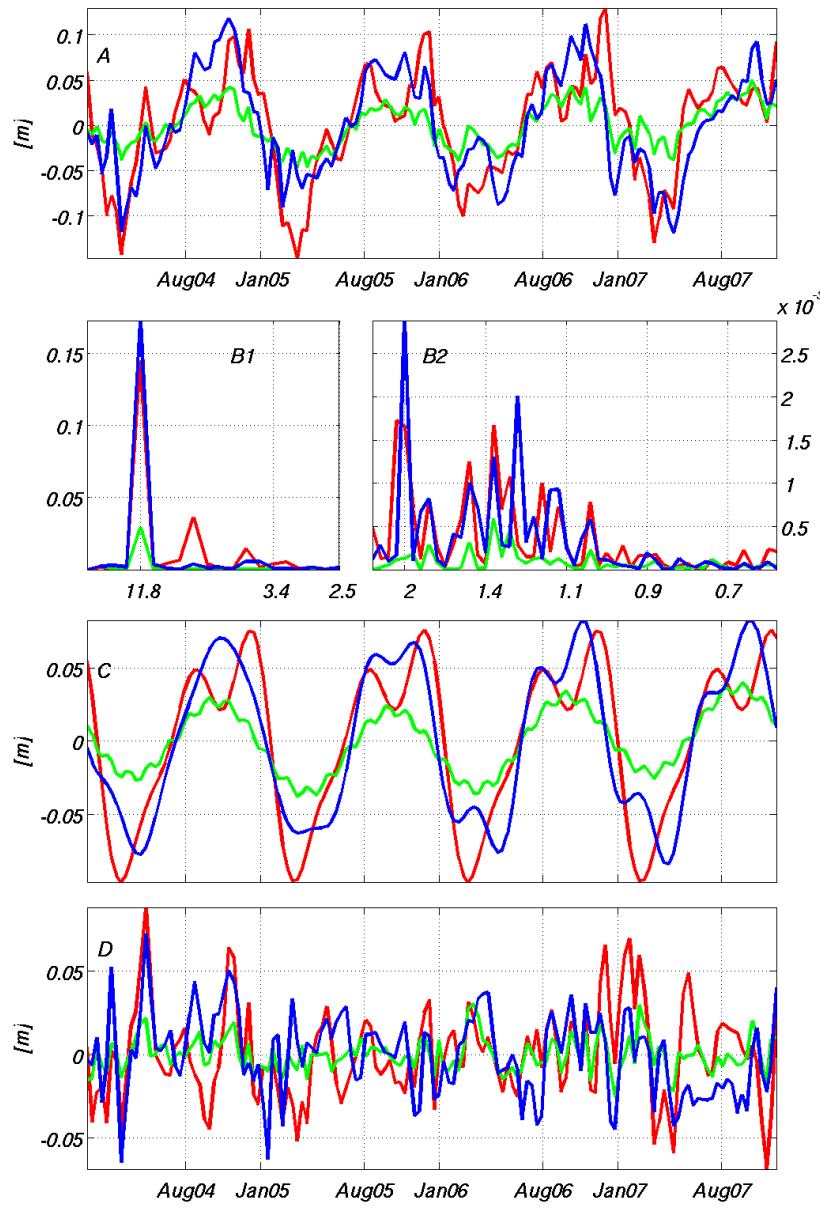

Fig. 10. (A) Time series of Mediterranean Sea mean surface elevation from MFS_V2.1, MFS_V2.2 simulations and satellite observation. The steric effect has been superimposed on the model results. (B) Power spectrum for observed (blue line) and modelled (MFS_V2.1 green, MFS_V2.2 red line) surface elevation. (C) Time series of Mediterranean Sea mean surface elevation reconstructed using only the first three dominant frequencies in the power spectrum. (D) Time series of Mediterranean Sea mean surface elevation reconstructed using all the frequencies removed from panel (C).

and data can be attributed here to the use of climatological monthly fields for the nesting in the Atlantic.

MFS_V2.1 fails both in reproducing the double summerautumn and the local maxima occurring in February. It is also clear that MFS_V2.1 underestimates the energy content in the remaining part of the frequency spectrum (Fig. 10d).

As further evaluation of the surface elevation, model results have been compared with available tide gauges (cyan dots in Fig. 1) data; observations have been averaged in time in order to remove tidal signal, model results have been sampled on the tide gauges positions. In this case too the steric effect has been superimposed to the model results.

The time series of the surface elevation, averaging all the available tide gauge station data from MFS_V2.1, MFS_V2.2 simulations and tide gauge observations are shown in Fig. 11.

Major differences with satellite-derived surface elevation concern the annual minima that in the tide gauge time series occur in January. Both the model implementations fail in reproducing this feature. Due to the absence of this minimum in the satellite observations, we argue that this is probably due to coastal processes not resolved with our model resolution. In this case too the MFS_V2.2 reproduces the amplitude of the seasonal signal and the occurrence of the double summer-autumn maxima better; this model configuration is also able to reproduce the less pronounced observed autumn maxima in 2007. Power spectra (Fig. 11 bottom panels) confirm that MFS_V2.2 is able to reproduce the energy content of the dominant frequencies (12, 6 and 4 months $^{-1}$ ), while MFS_V2.1 fails in simulating the 6- and 4-month oscillations. Differently from the satellite data, the tide gauge surface elevations also show a significant energy content at higher frequency (higher than 2.5 months $^{-1}$ ).

Figure 12 is a Taylor diagram (Taylor, 2001) which summarizes the relative skill with which MFS_V2.1 (green circles) and MFS_V2.2 (red circles) implementations simulate the temporal evolution of surface elevation recorded by the tide gauges. MFS_V2.2 correlation with observations is about 0.5 ; the standard deviation of the simulated field is slightly smaller than the observed standard deviation. MFS_V2.1 has a slightly higher correlation (0.6) with observations but strongly underestimated the amplitude of the variations, with a normalized standard deviation of about 0.3 . The lower correlation with the observation of MFS_V2.2 is due to the high frequency oscillations that in some cases are delayed with respect to the observations (Fig. 11 upper panel), producing higher error.

\section{Summary and conclusion}

In the framework of the MERSEA project, a new highresolution numerical model for the whole Mediterranean Sea has been implemented and successfully nested within a coarse resolution global model with the final goal of upgrading the hydrodynamic component of the Mediterranean Forecasting System. Major differences with a previous version of the MFS hydrodinamical model (Tonani et al., 2008) concern the representation of bottom topography, the surface forcing function for vertical components of the momentum and salinity, and the nesting between the regional Mediterranean and the global MERCATOR models (Drevillon et al., 2008) (see Table 1). The scope of this work is to investigate the improvements deriving from the nesting approach. The results of a twin experiment have been analyzed. The experiment has been carried out using two different implementations of the NEMO (Madec, 2008) model. The two simulations differ only in terms of nesting and related surface boundary conditions. The MFS_V2.1 version of the model reproduces the parameterization already used in Tonani et 

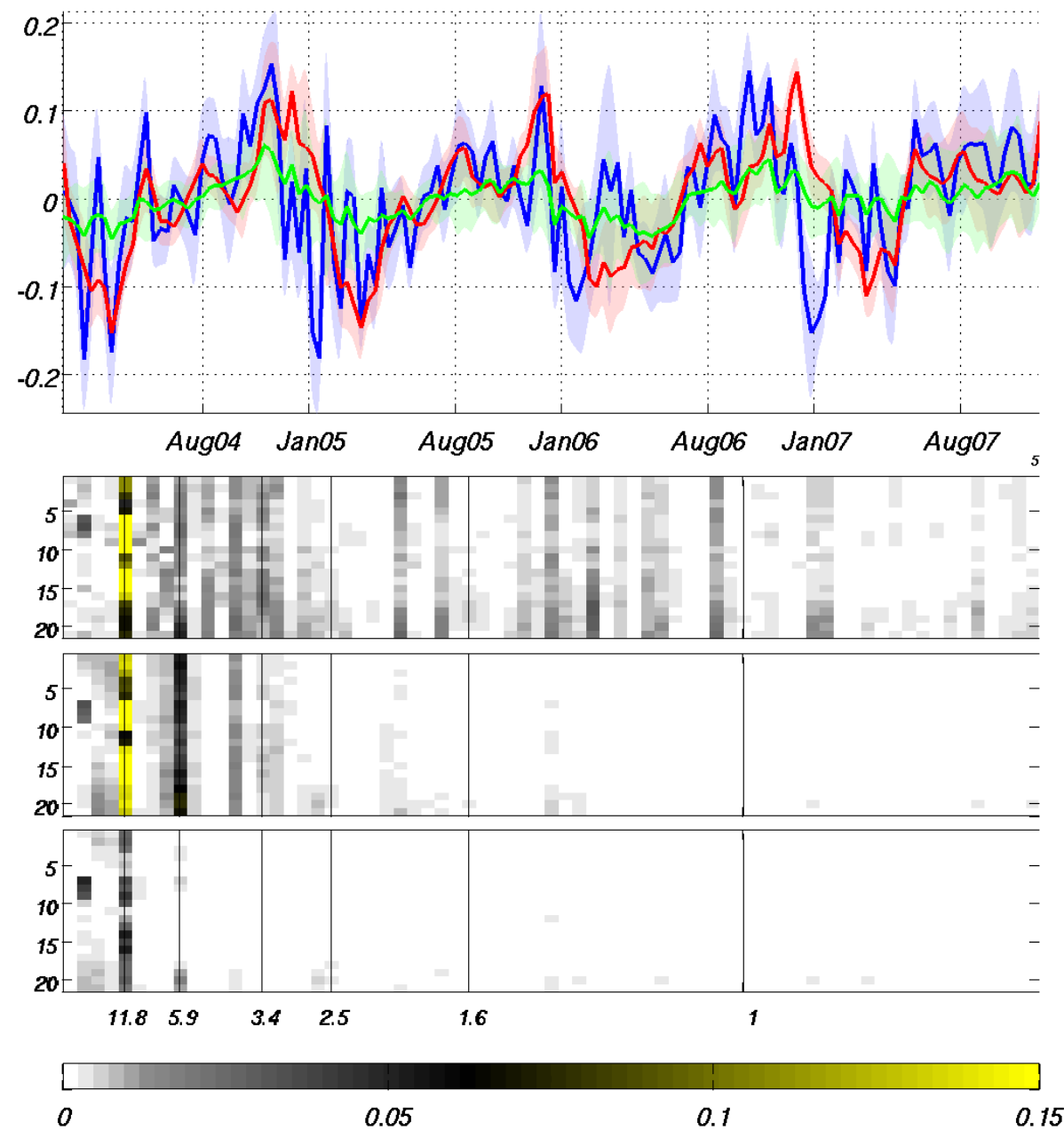

Fig. 11. Top panel: Time series of mean surface elevation from MFS_V2.1 (green line), MFS_V2.2 (red line) simulations and tide gauge observations (blue line). The steric effect has been superimposed on the model results. The shaded coloured areas show the two standard deviation ranges. Bottom panels: Power spectra for observed and modelled surface elevation (from top to bottom: observation, MFS_V2.2 and MFS_V2.1). X-axis indicate station number; $\mathrm{Y}$ axis indicate frequency in month $^{-1}$, colour indicate the energy in $\mathrm{m}^{2}$.

al. (2008); the model has three closed boundaries in the Atlantic (Fig. 1) where active tracers (temperature and salinity) are relaxed toward monthly climatological data; as a consequence of the closed-domain approach the mass is preserved using a correction factor in the Atlantic area that compensates the surface mass flux occurring in the Mediterranean. MFS_V2.2 has three open boundaries in the Atlantic where it is nested with the same monthly climatological fields used for the relaxation in the MFS_V2.1 version; as a consequence of the dynamical nesting, no particular correction needs to be applied to the surface forcing functions.

As a first guess the model is able to reproduce the Mediterranean observed dynamics with a skill comparable to previous model efforts in the Mediterranean Sea (Fig. 7). Major differences between the two simulations result concerning the proprieties of the inflowing Atlantic water (Fig. 8) and a seasonal variation of the Mediterranean water volume (Fig. 5).
In the closed domain implementation, a freshening of the inflowing Atlantic water proprieties has been observed (Fig. 8); this deterioration (Fig. 9) is due to the necessity of preserving the volume in the whole domain. As the Mediterranean Sea is a concentration basin, the correction factor applied in the Atlantic area is, in general, positive (water from the atmosphere into the ocean) with the obvious consequence of diluting the surface Atlantic waters. In order to overcome this problem alternative solutions have been adopted in the past, but in all the considered cases they represent compromises between physical coherent (realistic) representation of the surface processes and suitability of the numerical solution.

In Tonani (Tonani et al. 2008) the $(E-P-R)$ component of vertical velocity and salinity surface boundary conditions (Eqs. 1 and 2) is obtained through relaxation using surface climatological salinity; moreover, the flux correction applied in the Atlantic box does not affect the salinity. 


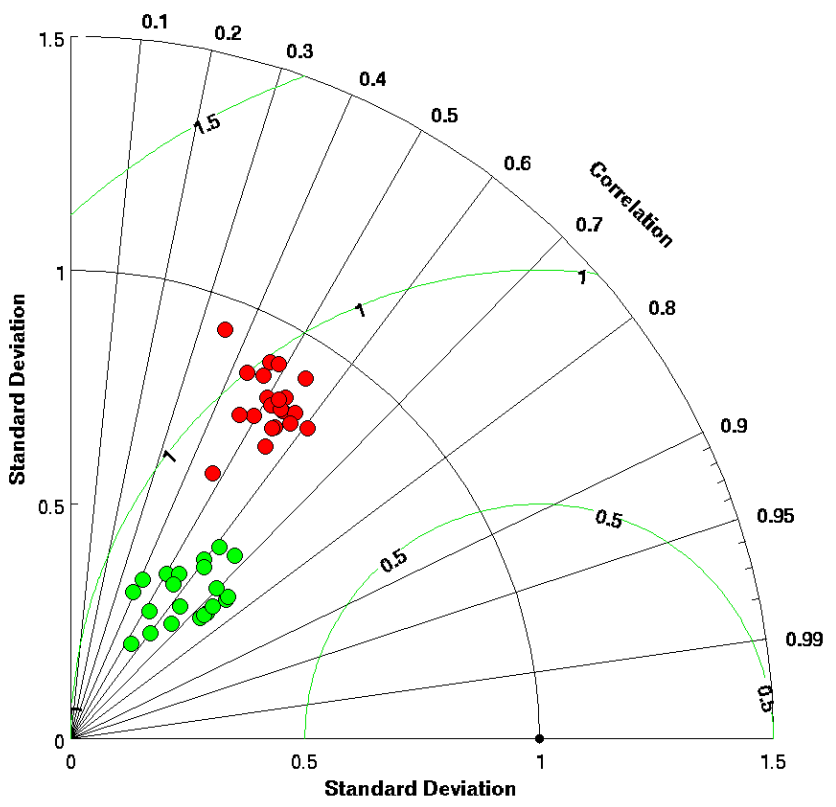

Fig. 12. Model implementation vs. tide gauge observation Taylor diagrams. Red circles indicate MFS_V2.2, green circles indicate MFS_V2.1.

This is equivalent to supposing that precipitation has same salinity as surface Atlantic water. Major disadvantage of this approach are: low reliability of surface fluxes for both vertical component of the momentum and salinity; this flux does not take into account real air-sea exchanges but only a difference with corresponding climatological values; surface boundaries for vertical velocity and salinity are not related each other (Beron-Vera et al., 1999) in the Atlantic area. This is clearly non-consistent but allows a reasonable solution within the Mediterranean Sea insofar as regards surface salinity values, and it is particularly suitable for operational purposes.

In the MFS_V2.1 (closed implementation) discussed in this work we used coherent surface boundary condition for vertical velocity and salinity; this approach gave us the possibility to have realistic surface fluxes over the Mediterranean Sea (Fig. 3) but at the same time it also causes the freshening of the Atlantic waters. On the contrary, in MFS_V2.2, using a nesting approach, the volume conservation issue is managed by the lateral boundary condition parameterization and there is no need to apply a correction factor to the surface fluxes; this allows a better representation of the inflowing Atlantic water proprieties (Figs. 8 and 9).

One of the major findings deriving from the nesting approach concerns a large scale seasonal oscillation of the Mediterranean volume (Fig. 5). The adopted lateral boundary condition allows the volume of the domain to vary according to the transport imposed by the nesting model and, at the same time, on the base of equilibrium between nested and nesting models continuity equations (4). Seasonal varia- tion of Mediterranean volume in the MFS_V2.1 implementation are due mostly to steric effect, while in MFS_V2.2 and in the observed datasets the steric effect seasonal cycle is modulated by oscillations with similar frequencies (Fig. 10a). As a consequence the amplitude of the 12-month period oscillation in MFS_V2.1 is underestimated.

In particular, the summer maximum observed in both the satellite data and tide gauges is reproduced by the model using the nesting approach (Fig. 10a and c). The dominant frequency in all the considered dataset (satellite, tide gauges and both model implementations) is about 12 months $^{-1}$; moreover, observations and MFS_V2.2 results are then modulated by oscillation with frequencies ranging between 3.5 and 6 months $^{-1}$.

Compared with satellite-derived data, in the open-domain simulation there is also the correct amount of energy at higher frequencies (ranging between 1 and 2 months $^{-1}$ ), while MFS_V2.1 strongly underestimates this part of the signal (Fig. 10b2). This is probably due to the fact that with a nesting approach the model has a greater degree of freedom and a larger number of oscillations are allowed. Dictated by operational needs, the future development will be to nest the model with high-frequency inter-annual fields from the MERCATOR operational system. A better temporal resolution of the nesting model should allow a more realistic reproduction of inter-annual variability in the Mediterranean Sea.

Edited by: M. Hecht

\section{References}

Béranger, K., Mortier, L., and Crépon, M.: Seasonal variability of water transports through the Straits of Gibraltar, Sicily and Corsica, derived from a high resolution model of the Mediterranean circulation, Progress in Oceanography, 66(2-4), 341-364, 2005.

Beron-Vera, F. J., Ochoa, J., and Ripa, P.: A note on boundary conditions for salt and freshwater balances, Ocean Model., 1, 111118, 1999.

Bozec, A., Bouruet-Aubertot, P., Béranger, K., and Crépon, M.: Mediterranean oceanic response to the interannual variability of a high-resolution atmospheric forcing: A focus on the Aegean Sea, J. Geophys. Res., 111, C11013, doi:10.1029/2005JC003427, 2006.

Cazenave, A., Dominh, K., Gennero, M. C., and Ferret, B.: Global mean sea level changes observed by Topex-Poseidon altimetry and ERS-1, Phys. Chem. Earth, 23, 1069-1075, 1998.

Demirov, E. and Pinardi, N.: The simulation of the Mediterranean Sea circulation from 1979 to 1993 . Part I: The interannual variability, J. Mar. Syst., 33-34, 23-50, 2002.

Desaubies, Y.: Mersea, Development of a European Ocean Monitoring and Forecasting System - Ocean and Marine applications for Gmes", in: Ocean Weather Forecasting: An Integrated View of Oceanography, Chapter 19,pp. 449-453, edited by: Chassignet, E. and Verron, J., Springer, ISBN: 1-4020-39816, doi:10.1007/1-4020-4028-8_19, 2006. 
Drevillon, M., Bourdallé-Badie, R., Derval, C., Drillet, Y., Lellouche, J. M., Rémy, E., Tranchant, B., Benkiran, M., Greiner, E., Guinehut, S., Verbrugge, N., Garric, G., Testut, C. E., Laborie, M., Nouel, L., Bahurel, P., Bricaud, C., Crosnier, L., Dombrosky, E., Durand, E., Ferry, N., Hernandez, F., Le Galloudec, O., Messal, F., and Parent, L.: The GODAE/MercatorOcean global ocean forecasting system: results, applications and prospects, J. Operational Oceanogr., 1(1), 51-57, 2008.

Estubier, A. and Lévy, M.: Quel schéma numérique pour le transport d'organismes biologiques par la circulation océanique, Note Techniquesdu Pôle de modélisation, Institut Pierre-Simon Laplace, 81 pp, 2000.

Fekete, B. M., Vörösmarty, C. J., and Grabs, W.: Global, Composite Runoff Fields Based on Observed River Discharge and Simulated Water Balances, Tech. Rep. 22, Global Runoff Data Cent., Koblenz, Germany, 1999.

Flather, R. A.: A tidal model of the northwest European continental shelf, Memories de la Societe Royale des Sciences de Liege, 6(10), 141-164, 1976.

Fukumori, I., Menemenlis, D., and Lee, T.: A near-uniform basinwide sea level fluctuation of the Mediterranean Sea, J. Phys. Oceanogr., 37, 338-358, 2008..

Greatbatch, R. J.: A note on the representation of steric sea level in models that conserve volume rather than mass, J. Geophys. Res., 99(C6), 12767-12771, 1994.

Kistler, R., Kalnay, E., Collins, W., Saha, S., White, G., Woollen, J., Chelliah, M., Ebisuzaki, W., Kanamitsu, M., Kousky, V., Van den Dool, H., Jenne, R., and Fiorino, M.: The NCEP-NCAR 50Year Reanalysis: Monthly Means CD-ROM and Documentation, B. Am. Meteorol. Soc., 82, 247-268, 2001.

Kondo, J.: Air-sea bulk transfer coefficients in diabatic conditions, Bound.-Lay. Meteorol., 9, 91-112, 1975.

Kourafalou, V. H. and Barbopoulos, K.: High resolution simulations on the North Aegean Sea seasonal circulation, Ann. Geophys., 21, 251-265, 2003, http://www.ann-geophys.net/21/251/2003/.

Lascaratos, A., Williams, R. G., and Tragou, E.: A mixedlayer study of the formation of Levantine intermediate water, J. Geophys. Res., 98, 14739-14749, 1993.

Levitus, S.: NODC World Ocean Atlas 1998 data, report: NOAACIRES Clim. Diag. Cent. Boulder, Colorado, 1998.

Lévy, M., Estublier, A., and Adec, G.: Choice of an advection scheme for biogeochemical models, Geophys. Res. Lett., 28(19), 3725-3728, 2001.

Madec, G., Delecluse, P., Imbard, M., and Levy, C.: OPA8.1 Ocean general Circulation Model reference manual. Note du Pole de modelisazion, Institut Pierre-Simon Laplace (IPSL), France, 11, 1998.

Madec, G.: NEMO ocean engine, Note du Pole de modélisation, Institut Pierre-Simon Laplace (IPSL), France, No 27 ISSN No 1288-1619, 2008.

Marchesiello, P., McWilliams, J. C., and Shchepetkin, A.: Open boundary conditions for long term integration of regional oceanic models, Ocean Model., 3, 1-20, 2001.

Mariotti, A., Struglia, M. V., Zeng, N., and Lau, K. M.: The Hydrological Cycle in the Mediterranean Region and Implications for theWater Budget of the Mediterranean Sea., J. Climate, 15, 1674-1690, 2002.

Mellor, G. L. and Ezer, T.: Sea level variations induced by heating and cooling: An evaluation of the Boussinesq approximation in ocean models, J. Geophys. Res., 100(C10), 20565-20577, 1995.

Menemenlis, D., Fukumori, I., and Lee, T.: Atlantic to Mediterranean sea level difference driven by winds near Gibraltar Strait, J. Phys. Oceanogr., 37, 359-376, 2007.

Oddo, P. and Pinardi, N.: Lateral open boundary conditions for nested limited area models: A scale selective approach, Ocean Model., 20, 134-156, 2008.

Orlanski, I.: A simple boundary condition for unbounded hyperbolic flows, J. Comput. Phys., 21, 251-269, 1976.

Pinardi, N. and Flemming, N. C.: The Mediterranean Forecasting System Science Plan, EuroGOOS Publication no. 11, Southampton Oceanography Centre, 48 pp., ISBN 0-904175-35-9, 1998.

Pinardi, N., Allen, I., Demirov, E., De Mey, P., Korres, G., Lascaratos, A., Le Traon, P.-Y., Maillard, C., Manzella, G., and Tziavos, C.: The Mediterranean ocean forecasting system: first phase of implementation (1998-2001), Ann. Geophys., 21, 3-20, 2003,

http://www.ann-geophys.net/21/3/2003/.

Pinardi, N., Arneri, E., Crise, A., Ravaioli, M., and Zavatarelli, M.: The physical, sedimentary and ecological structure and variability of shelf areas in the Mediterranean Sea, The Sea, vol. 14, edited by: Robinson, A. R. and Brink, K., Harvard University Press, Cambridge, USA 1243-1330, 2006.

Poulain, P.-M., Barbanti, R., Font, J., Cruzado, A., Millot, C., Gertman, I., Griffa, A., Molcard, A., Rupolo, V., Le Bras, S., and Petit de la Villeon, L.: MedArgo: a drifting profiler program in the Mediterranean Sea, Ocean Sci., 3, 379-395, 2007, http://www.ocean-sci.net/3/379/2007/.

Pujol, M. I. and Larnicol, G.: Mediterranean Sea eddy kinetic energy variability from 11 years of altimetric data, J. Mar. Syst., 58(3-4), 121-142, 2005.

Raicich, F.: On fresh water balance of the Adriatic Sea, J. Mar. Syst., 9, 305-319, 1996.

Robinson, A. R. and Golnaraghi, M.: The physical and dynamical oceanography of the Mediterranean Sea, in: Ocean Processesin ClimateD ynamics: Global and MediterraneanE xamples, edited by: Malanotte-Rizzoli, P. and Robinson, A. R., pp. 255306, Kluwer Acad., Norwell, Mass., 1994.

Roussenov, V., Stanev, E., Artale, V., and Pinardi, N.: A seasonal model of the Mediterranean Sea general circulation, J. Geophys. Res., 100(C7), 13515-13538, 1995.

Taylor, K. E.: Summarizing multiple aspects of model performance in a single diagram, J. Geophys. Res., 106, 7183-7192, 2001.

Testor, P., Béranger, K., and Mortier, L.: Modeling the deep eddy field in the southwestern Mediterranean: the life cycle of Sardinian Eddies, Geophys. Res. Lett., 32(13), L13602, doi:10.1029/2004GL022283, 2005..

Tonani, M., Pinardi, N., Dobricic, S., Pujol, I., and Fratianni, C.: A high-resolution free-surface model of the Mediterranean Sea, Ocean Sci., 4, 1-14, 2008, http://www.ocean-sci.net/4/1/2008/.

Van Leer, B.: Towards the Ultimate Conservative Difference Scheme, V. A Second Order Sequel to Godunov's Method, J. Comput. Phys., 32, 101-136, 1979.

Xie, P. and Arkin, P. A.: Global precipitation: A 17-year monthly analysis based on gauge observations, satellite estimates, and numerical model outputs, B. Am. Meteorol. Soc., 78, 2539-2558, 1997. 